Supporting Information

\title{
Composition-Tunable PtCu Alloy Nanowires and Electrocatalytic Synergy for Methanol Oxidation Reaction
}

Yuan Liao, ${ }^{\mathrm{a}}$ Gang Yu, ${ }^{\mathrm{a} *} \mathrm{Yu}$ Zhang, ${ }^{\mathrm{a}}$ Tingting Guo, ${ }^{\mathrm{a}}$ Fangfang Chang, ${ }^{\mathrm{a}, \mathrm{b}}$ and Chuan-Jian Zhong ${ }^{\mathrm{b}, *}$

a State Key Laboratory of Chemo/Biosensing and Chemometrics, College of Chemistry and Chemical Engineering, Hunan University, Changsha 410082, P. R. China

b Department of Chemistry, State University of New York at Binghamton, Binghamton, NY, 13902, USA

*Corresponding authors:

Fax: +86-0731-8471-3642. Tel.: +86-0731-8882-2275. E-mail: yuganghnu@163.com (G. Yu);

Fax: +1-607-777-4478. Tel.: +1-607-777-4605. E-mail: cjzhong@binghamton.edu (C.J. Zhong). 


\section{Additional Experimental Data:}

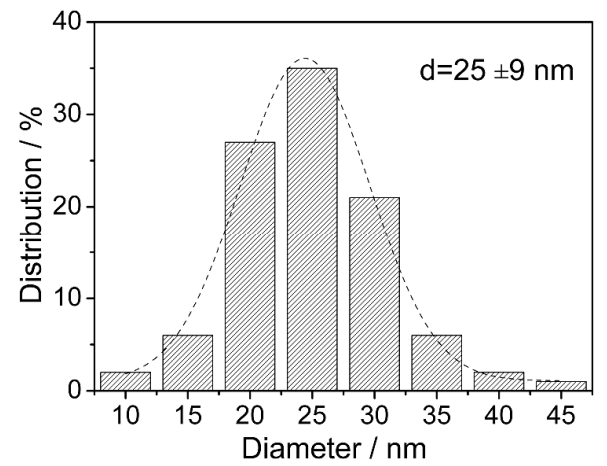

Figure S1. The size distribution of the $\mathrm{Pt}_{32} \mathrm{Cu}_{68} \mathrm{NWs}$.
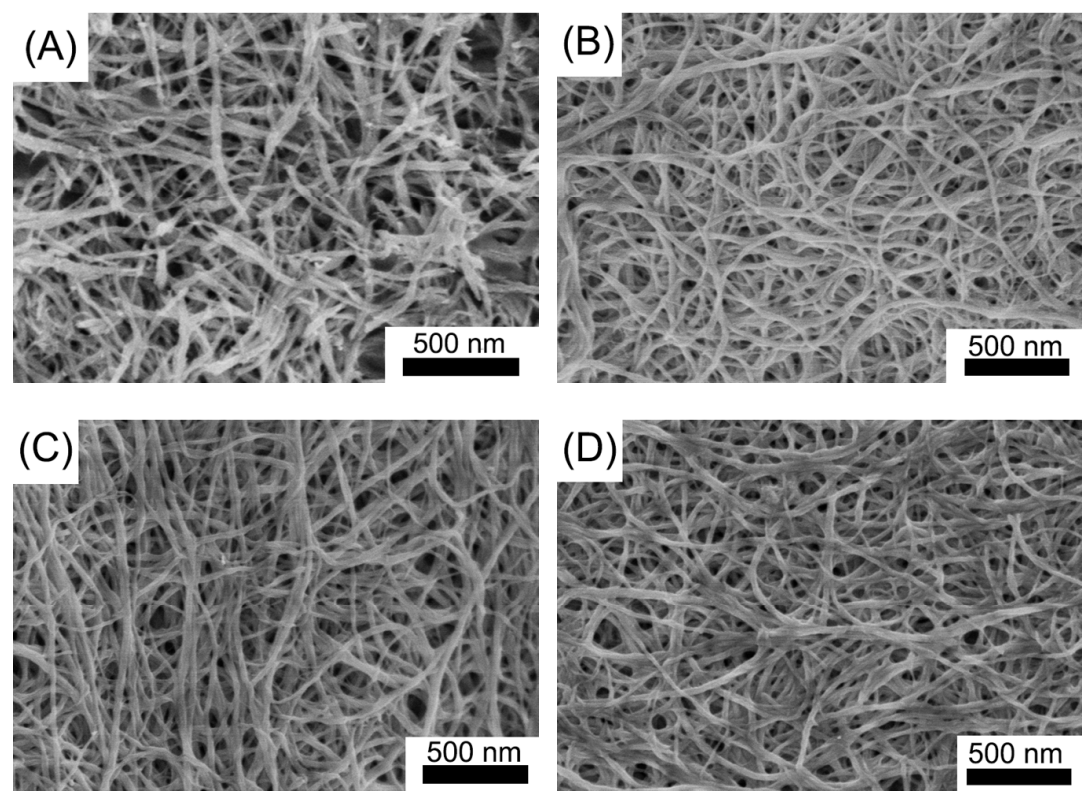

Figure S2. FESEM of (A) $\left.\mathrm{Pt}_{70} \mathrm{Cu}_{30}, \mathrm{~B}\right) \mathrm{Pt}_{45} \mathrm{Cu}_{55},(\mathrm{C}) \mathrm{Pt}_{21} \mathrm{Cu}_{79}$, and (D)Pt NWs.

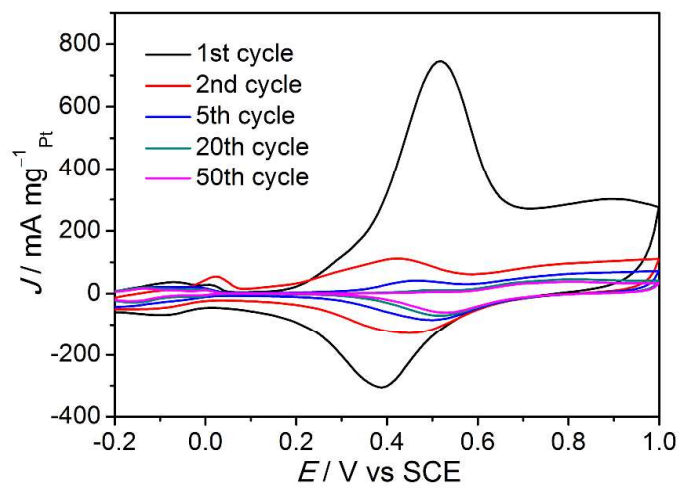

Figure S3. CV curves of $\mathrm{Pt}_{32} \mathrm{Cu}_{68} \mathrm{NWs}$ in $0.5 \mathrm{M} \mathrm{H}_{2} \mathrm{SO}_{4}$ solution purged with $\mathrm{N}_{2}$ at a scan rate of $50 \mathrm{mV} \mathrm{s}^{-1}$. 


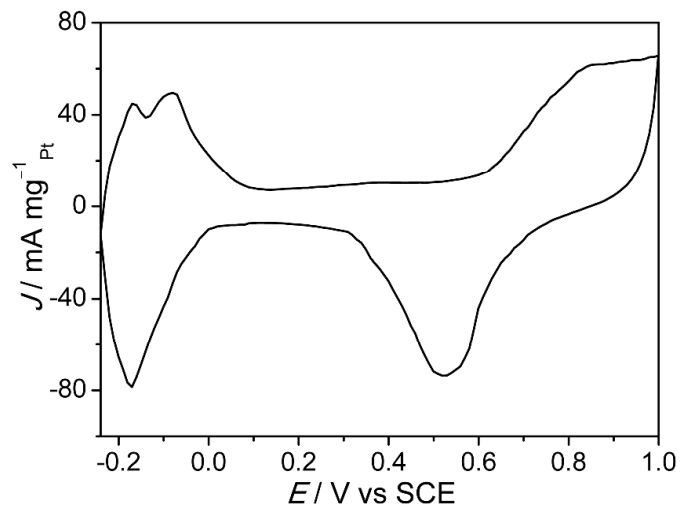

Figure S4. CV curve of commercial Pt/C catalysts in $0.5 \mathrm{M} \mathrm{H}_{2} \mathrm{SO}_{4}$ solution purged with $\mathrm{N}_{2}$ at a scan rate of $50 \mathrm{mV} \mathrm{s}^{-1}$.

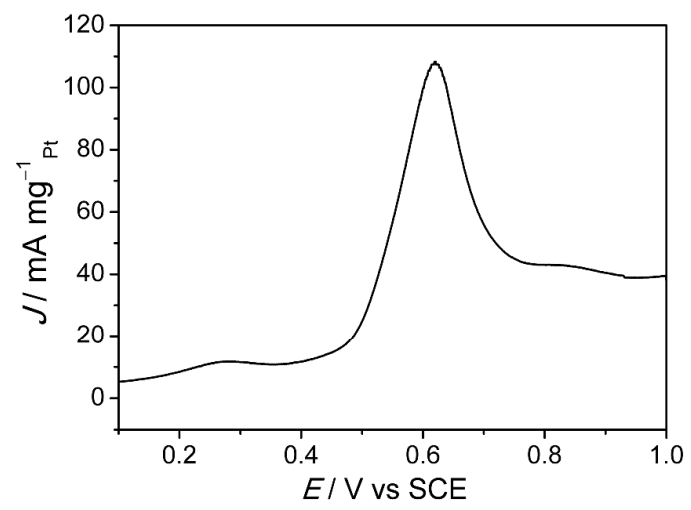

Figure S5. CO stripping curve of commercial Pt/C catalysts in $0.5 \mathrm{M} \mathrm{H}_{2} \mathrm{SO}_{4}$ solution at a scan rate of $50 \mathrm{mV} \mathrm{s}^{-1}$.
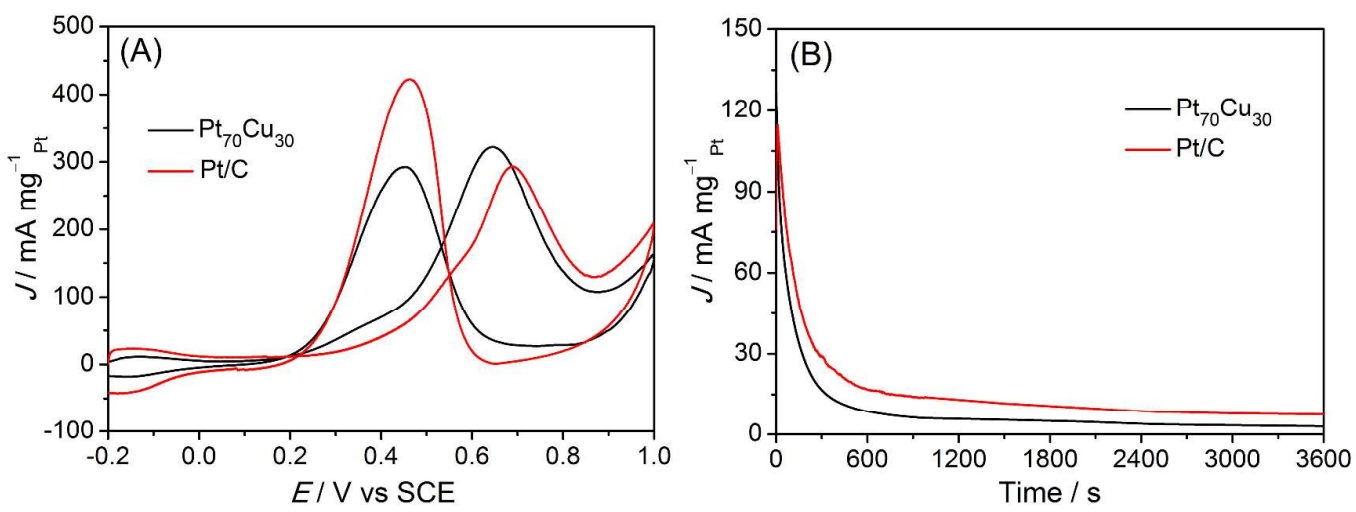

Figure S6. (A) CV curves of $\mathrm{Pt}_{70} \mathrm{Cu}_{30} \mathrm{NWs}$ and commercial Pt/C catalysts in $0.5 \mathrm{M} \mathrm{H}_{2} \mathrm{SO}_{4}+0.5$ $\mathrm{MCH}_{3} \mathrm{OH}$ solution purged with $\mathrm{N}_{2}$ at a scan rate of $50 \mathrm{mV} \mathrm{s}^{-1}$, (B) Chronoamperometric curves of $\mathrm{Pt}_{70} \mathrm{Cu}_{30} \mathrm{NWs}$ and commercial Pt/C catalysts in $0.5 \mathrm{M} \mathrm{H}_{2} \mathrm{SO}_{4}+0.5 \mathrm{M} \mathrm{CH}_{3} \mathrm{OH}$ solution at $0.55 \mathrm{~V}$. 

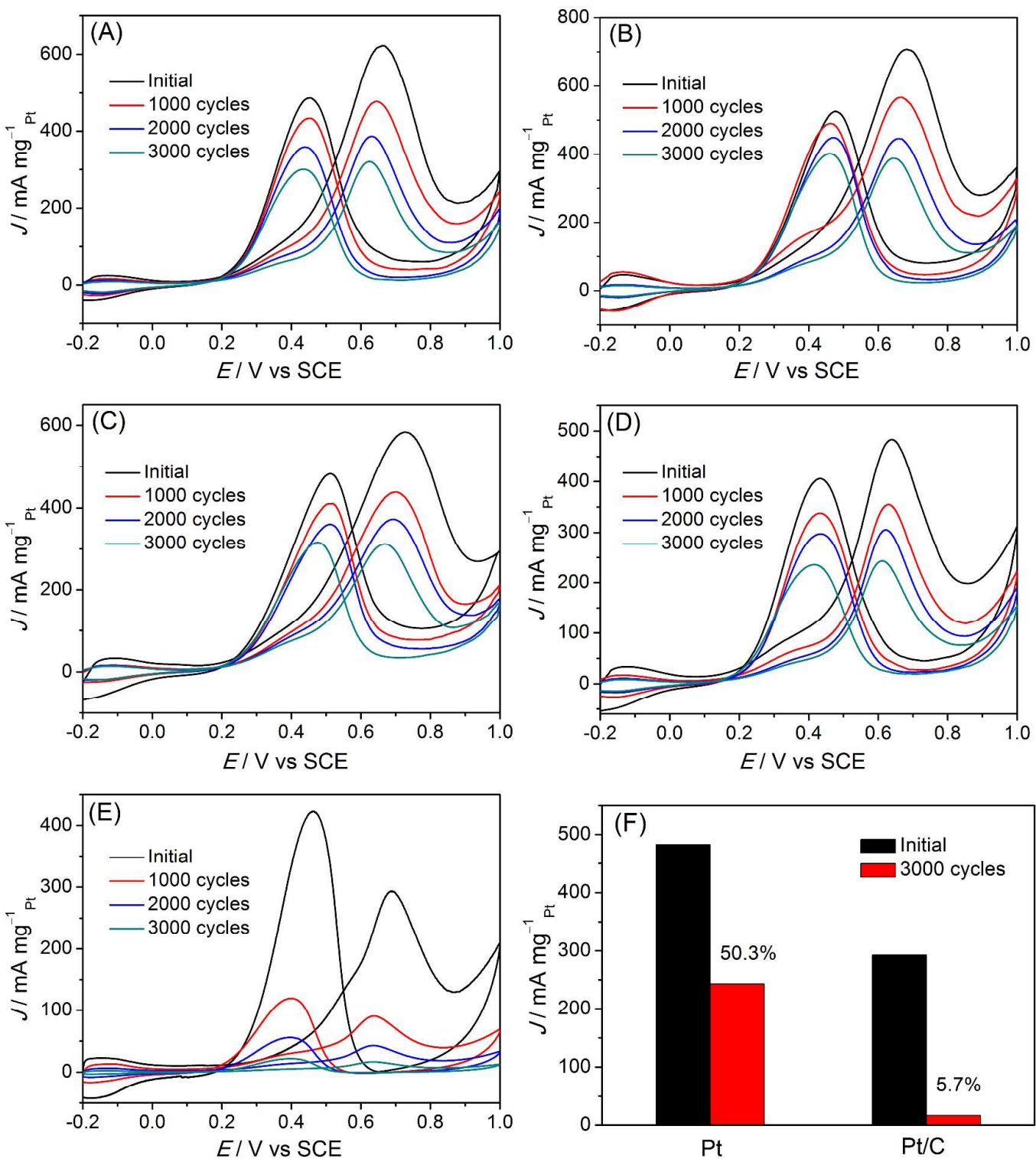

Figure S7. CV curves of (A) $\mathrm{Pt}_{45} \mathrm{Cu}_{55}$, (B) $\mathrm{Pt}_{32} \mathrm{Cu}_{68}$, (C) $\mathrm{Pt}_{21} \mathrm{Cu}_{79}$, (D) Pt NWs, (E) commercial $\mathrm{Pt} / \mathrm{C}$ catalysts before and after 1000-3000 cycles. $\mathrm{CV}$ curves were recorded in $0.5 \mathrm{M} \mathrm{H}_{2} \mathrm{SO}_{4}+0.5$ $\mathrm{MCH}_{3} \mathrm{OH}$ solution purged with $\mathrm{N}_{2}$ at a scan rate of $100 \mathrm{mV} \mathrm{s}^{-1}$. (F) Comparison of mass activities for methanol oxidation before and after 3000 cycles for Pt NWs and commercial Pt/C catalysts.

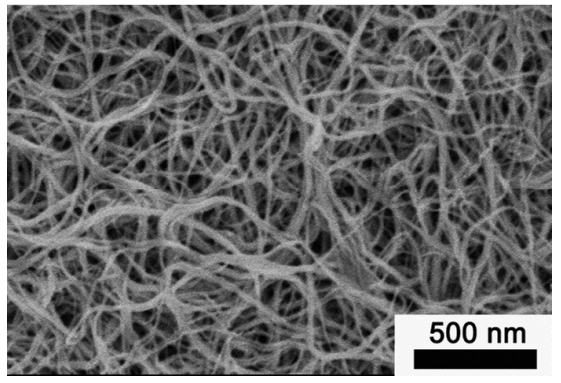

Figure S8. FESEM of $\mathrm{Pt}_{32} \mathrm{Cu}_{68} \mathrm{NWs}$ after 3000 cycles of $\mathrm{CV}$ test. 